\title{
Predation on early ontogenetic life stages and its effect on recruitment into a marine epifaunal community
}

\author{
Richard W. Osman ${ }^{1}$, Robert B. Whitlatch ${ }^{2}$ \\ ${ }^{1}$ Academy of Natural Sciences, Benedict Estuarine Research Center, 10545 Mackall Road, St. Leonard, Maryland 20685, USA \\ ${ }^{2}$ Department of Marine Sciences, University of Connecticut, Groton, Connecticut 06340, USA
}

\begin{abstract}
In a New England (USA) subtidal hard-substrate community, 2 species of very small gastropods, Anachis lafresnayi and Mitrella lunata, prey on several species of newly settled ascidians. Preliminary experiments indicated that this predation drastically changes ascidian recruitment patterns. In order to examine this phenomenon more fully, an extensive series of field experiments using artificial substrates was performed over a 2 yr period between 1991 and 1992. In 1992, weekly experiments were conducted over the complete recruitment season between July and October. Comparisons of the experiments were made to test for any weekly or annual variation in the effect of these micro-predators on recruitment. Results demonstrated that the predators (1) were fairly specific in their prey preferences, (2) could eliminate prey species regardless of their settlement density, (3) switched prey in response to changes in prey species abundance, and (4) affected recruitment throughout the entire settlement season. These results indicate that processes affecting post-settlement life stages contribute significantly to the overall dynamics of communities and must be considered along with the much better documented effects of larval supply, adult predators, and physical disturbance.
\end{abstract}

KEY WORDS: Recruitment - Larval settlement - Predation - Marine benthic invertebrates - Anachis lafresnayi - Mitrella lunata. Ascidians

\section{INTRODUCTION}

For many marine benthic invertebrates the recruitment of new individuals into a population or community involves 2 early ontogenetic stages: (1) planktonic larvae, which settle to the bottom, undergo metamorphosis, and begin a permanent benthic existence; and (2) post-settlement individuals, which develop and grow over hours to weeks into recognizable recruits or juveniles. The importance of mortality during this postsettlement period to recruitment in marine benthic communities was first emphasized by Thorson (1966). He clearly described the potential of small meiofaunal predators to affect recruitment by preying on small post-settlement individuals. More recently, others (e.g. Keough \& Downes 1982, Watzin 1983, Luckenbach 1984, Young \& Chia 1984, Connell 1985, McGuinness \& Davis 1989, Osman et al. 1990, 1992, Stoner 1990, Roegner 1991, Osman \& Abbe 1994) have also demon- strated the importance of mortality of post-settlement individuals in controlling recruitment into benthic invertebrate communities. Vadas et al. (1992) recently reviewed the wealth of studies detailing both the rich variety of causes and the importance of post-settlement mortality in benthic algal communities.

It is clear from these studies that the usually tiny post-settlement individuals can be extremely different from larger juveniles and adults in their interactions with their new environment. As Thorson (1966) and others (e.g. Sutherland 1974, Watzin 1983, Young \& Chia 1984, Stoner 1990, Vadas et al. 1992) have described, the small size of post-settlement life stages, if nothing else, makes them vulnerable to predators or herbivores that may not interact with adults. For algae, with their often intricate life cycles, ontogenetic variation in survivorship can result in a bimodal or even more complex distribution as vulnerability and causes of mortality change with each life stage (Vadas et al. 
1992). In addition to predation, factors such as herbivory (Underwood 1980, Dean et al. 1984, 1988), intra- and interspecific competition (Caffey 1985, Bertness 1989, Reed 1990), desiccation (Hruby \& Norton 1979, Brawley \& Johnson 1991), siltation (Dayton 1973, 1975, DeVinny \& Volse 1978), fluctuations in light and temperature (Dayton \& Tegner 1984, Deysher \& Dean 1986), or the development of hypoxia (Osman \& Abbe 1994) can cause differential mortality among postsettlement individuals.

Previously, we reported on the potential of 2 tiny ( 3 to $15 \mathrm{~mm}$ ), but extremely common gastropods, Anachis lafresnayi (originally identified by us as A. avara) and Mitrella lunata, to prey on newly settled ascidians and alter the recruitment into a New England (USA) rockysubtidal, sessile community (Osman et al. 1992). Our observations indicated that ascidians were abundant only at sites where the snails were absent and preliminary experiments suggested that both snails were fairly selective, preying almost exclusively on the encrusting ascidians Botryllus schlosseri, Diplosoma sp. (probably D. macdonaldi), and possibly Botrylloides diegensis. This selective predation caused significant reductions in the recruitment of $B$. schlosseri and Diplosoma sp., resulting in their reduced abundance or absence from the developing community. We conducted similar experiments in the summers of 1991 and 1992 in order to determine whether the predators could continue to affect ascidian recruitment regardless of annual and seasonal variations in the settlement rates of the dominant species within the community. We also examined whether the 2 species of predators differed in their effect on recruitment as a consequence of differences in prey selection, and whether the prey species had an escape in size that could limit the predator's influence.

\section{METHODS}

Experiments were conducted on a floating raft moored in $\sim 3 \mathrm{~m}$ of water behind a jetty at Avery Point, Connecticut, USA, in the eastern end of Long Island Sound (see Osman et al. 1992 for greater detail). Colonial (Botryllus schlosseri, Botrylloides diegensis, and Diplosoma sp.) and solitary ascidians (Molgula manhattensis, Ciona intestinalis, and Styela clava) were the dominant epifaunal species found on rocks, jetties, pilings, and algae at this site. They often accounted for more than $80 \%$ of the cover. Other taxa included sponges (Halichondria sp., Haliclona sp., and Leucosolenia sp.), hydroids (Obelia sp.), serpulid polychaetes (Spirorbis spp. and Hydroides dianthus), barnacles (Balanus amphitrite, Balanus eburneus, and Semibalanus balanoides), and bryozoans (Cryptosula pallas- iana, Schizoporella errata, Bugula turrita, and Bowerbankia gracilis). All of these species, as well as rarer ones, were collected on recruitment panels exposed for $1 \mathrm{wk}$ periods at the site. Both Anachis lafresnayi and Mitrella lunata are common in the general area occurring at mean densities between 0.5 and 1.0 ind. $\mathrm{dm}^{-2}$ as well as in mixed species aggregations of $>20$ ind. $\mathrm{dm}^{-2}$. As we have previously reported (Osman et al. 1992), ascidians are rare or absent at locations where we have found $A$. lafresnayi and $M$. lunata present. Both snails were absent at the study site.

Main experiments. The goal of our main experiments was to measure the effects of Anachis lafresnayi and Mitrella lunata on recruitment of all species naturally settling at the time of each experiment. In 1991 and 1992 we conducted identical experiments with both species of gastropods, 5 sets of experiments in 1991 and 15 in 1992. We used similar experimental methods to those of Osman et al. (1992) with the main change being the haphazard assignment of both snails and panels to cages in order to eliminate potential cage effects. Briefly, we used 2 groups of ten $7.5 \times 2.5 \mathrm{~cm}$ roughened, $1.5 \mathrm{~mm}$ thick PVC panels in each experiment. On Day 1 of each experiment, 10 panels were hung beneath the raft in a vertical orientation with both sides exposed equally to settling larvae. On Day 2, each of 10 replicate, $2.5 \times 7.5 \times 9 \mathrm{~cm}$ cages was partitioned into 2 equal chambers using 1 of the 10 panels exposed on Day 1 (see Fig. 2 in Osman et al. 1992). Cages were constructed using small plastic microscope slide boxes and had 100 to 150 holes, $2 \mathrm{~mm}$ in diameter, in their walls which allowed water exchange but prevented the gastropods from escaping. A single snail was placed in a chamber, thereby exposing one surface of the central panel to the predator while keeping the opposite surface predator-free. At the same time the second group of 10 substrates was exposed to settling larvae in the same manner as the group exposed on Day 1. On Day 3 and all subsequent days, the group of panels inside cages were switched with those in the group outside (Table 1). This allowed unrestricted recruitment to both surfaces of a panel on one day, followed by confinement in a cage on alternate days. In addition, each time the panels were switched, the cages were replaced by 10 clean cages to which panels were haphazardly assigned and the 10 snails were pooled and reassigned haphazardly to the 10 cages. Rarely, a snail died during an experiment; if this occurred the gastropod was replaced by a new individual. Each experiment was started with new snails that had never been used in any experiments and all snails were returned to the field at the end of each experiment.

This design resulted in the treatment surface of each panel being exposed to a predator on alternate days 
while its paired surface was kept free of predators. The haphazard assignment of panels and snails to cages was done to 'randomize' any effects of differences among individual snails or cages within an experiment.

The cages were suspended at a depth $1 \mathrm{~m}$ below the raft. Experiments ran for either 10 or $18 \mathrm{~d}$ with panels sampled after accumulating 4 or $8 \mathrm{~d}$, respectively, in a cage. Thus, the first group of panels was sampled either on Day 9 or 17 and the second group on Day 10 or 18 (Table 1). In 1991, Expt 1 was begun on 30 June and was sampled on 8-9 July. Expts 2 and 3 ran for overlapping $18 \mathrm{~d}$ periods with Expt 2 being sampled on 24-25 July and Expt 3 being sampled on 9-10 August. Expt 4 ran for only $10 d_{;}$it was discontinued prior to the arrival of Hurricane Bob on 22 August. Expt 5 was begun on 23 August and sampled after $18 \mathrm{~d}$ (8-9 September). In 1992, all 15 experiments were run for $10 \mathrm{~d}$. Expt 1 was begun on 30 June and all remaining experiments were begun every $8 \mathrm{~d}$. Expt 15 was sampled
28-29 October. All new experiments were begun with new panels and new snails. All individuals or colonies of all species were counted on both the control and treatment surfaces of each panel.

In 1992, 3 additional experiments were conducted using the tiny $(3 \mathrm{~mm})$ herbivorous gastropod Lacuna vincta. These experiments were originally designed as a pilot study to examine whether this species had any effect on the recruitment of macroalgae. The design was the same as the Anachis lafresnayi and Mitrella lunata experiments except that $4 \mathrm{~L}$. vincta were used in each predator chamber and, in order to expose panels to light, cages were constructed of clear plastic and both cages and uncaged panels were hung from arms extending from the side of the raft. After the short, $10 \mathrm{~d}$ exposure period we could not identify any of the recruiting algae on either treatment. However, all invertebrates recruiting were counted and we used these experiments to test whether differences between

Table 1. Experimental design and sampling dates. The schedules for both 18 and $10 \mathrm{~d}$ experiments are shown with initial exposure $(E)$, exposure to recruiting larvae $(-)$, days inside cages $(C)$, and final sampling $(\mathrm{S})$ for both groups of panels indicated

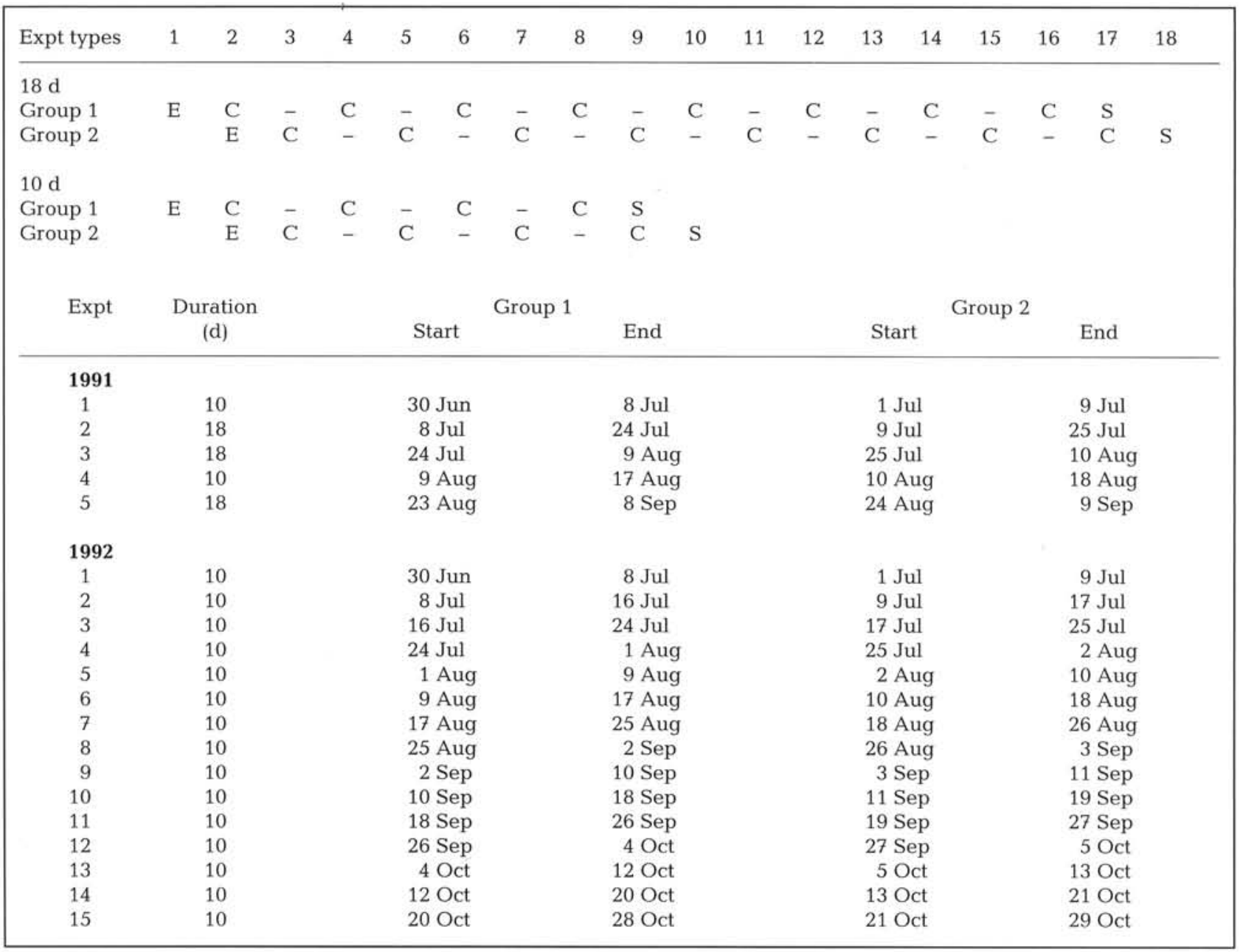


paired treatments could result from the activity of any mobile species regardless of whether it ingested any of the recruits. The experiments were conducted consecutively with the first begun on 10 August and the third sampled 31 August and 1 September. These time periods roughly corresponded to A. lafresnayi and $M$. lunata Expts 6 to 8.

Analyses. During the course of the study the recruitment rates of most species varied greatly resulting in each experiment being conducted at different, uncontrolled recruitment densities. Therefore, we analyzed the recruitment rate of each of the most abundant taxa separately for each experiment. We did not adjust the significance level of any statistical test to account for possible error associated with the large number of analyses. However, we did ignore any effects that were confined to a single experiment.

We designed all experiments to use the difference between the paired treatment and control surfaces of each panel as an estimate of the effect of the predator. Paired $t$-tests were used to test whether these differences were significantly different from 0 .

We also conducted 3 additional analyses. Firstly, it is possible that temporal changes in predation rates on 1 prey species could be influenced by changes in abundance of 1 or more of the other species, particularly if there are differences in prey preference. We had no a priori hypothesis as to which prey species would affect predation on other species or the magnitude of any possible effect. Therefore, we explored whether such effects might exist by using stepwise multiple regression. In these regressions we examined whether the percent mortality of each of the dominant recruiting species attributed to predation was possibly influenced by changes in abundance of the other recruiting species. In these analyses the ratio of the difference between paired treatment and control surfaces to control surfaces was used as a measure of the proportion of mortality resulting from predation. These estimates were regressed as a function of the corresponding abundances on control surfaces of the other dominant species. Each regression model used a forward selection technique with a significance level of 0.05 used as a criterion for inclusion of any species in the model.

Secondly, to examine the effect of changing abundances of recruits on predation, we analyzed the pooled 1991 and 1992 data using mixed-model 2-way ANOVAs with treatment (predator vs control) as a fixed effect and experiment $(=20$ uncontrolled differences in recruit abundance) as a random factor. Analyses were conducted for each of the prey species with each of the predators and the data were log-transformed to correct for heterogeneity in variances.

Finally, to examine the overall effects on the recruiting community in 1992, we compared the distribution of available prey as observed on control surfaces to the distribution of recruits in the presence of snails. We also contrasted the prey selection of the 2 gastropods. As an estimate of the number of each prey species consumed in each experiment, we used the differences between paired control and treatment surfaces. For each experiment the data for all surfaces within each category (control surfaces, predator surfaces, or calculated prey) were used to calculate frequency distributions. A log-likelihood ratio ( $G$-test) was used in all comparisons of distributions.

Auxiliary experiments. In order to delimit the interactions between the predators and their prey, 2 other types of experiments were conducted. First, in 1991 an experiment was conducted to examine whether the predation rate on the 2 principal prey species, Botryllus schlosseri and Diplosoma sp., was influenced by colony size or the species of predator, Anachis lafresnayi or Mitrella lunata. We used cages and panels identical to those in the main experiment. In this experiment 2 types of panel treatments were used; those with larger recruits consisting of 1 wk old ascidian colonies and those with smaller recruits 1 to $2 \mathrm{~d}$ in age. For Diplosoma sp. large recruits averaged $4.16 \pm$ $1.83 \mathrm{~mm}$ SE in diameter (10.6 \pm 3.26 zooids $)$ and small recruits were $1.11 \pm 0.25 \mathrm{~mm}$ ( $2.35 \pm 0.65$ zooids). For $B$. schlosseri large recruits had a mean diameter of $5.01 \pm 1.93 \mathrm{~mm}$ (approximately 7 to 8 zooids) and small recruits were $1.17 \pm 0.26 \mathrm{~mm}$ (approximately 1 to 2 zooids). Large recruit treatment panels each had 6 to 10 colonies and panels with small recruits each had 12 to 18 colonies. Five replicate panels of each prey size were exposed in the field for $24 \mathrm{~h}$ without (controls) or with a single predator (either A. lafresnayi or M. lunata). The mortality among treatments was compared using a 4-way ANOVA: 2 prey species $\times 2$ predator species $\times 2$ prey sizes $\times 2$ treatments (predator vs control). For the analysis, the percent mortality data were transformed using an arcsine-square-root transformation (Sokal \& Rohlf 1981).

Secondly, in both years experiments were conducted to examine the direct effects of each of the 2 predators on controlled densities of individual prey species. These experiments were part of a larger study of the functional responses of the 2 predators (Whitlatch \& Osman unpubl.). Here we use them to examine the effects of the predators on several species which settled in low abundances on our experimental substrates. Briefly, in these experiments panels were exposed in the laboratory to competent larvae of 1 of 5 species of ascidians, Botrylloides diegensis, Botryllus schlosseri, Ciona intestinalis, Molgula manhattensis, or Styela clava. After $24 \mathrm{~h}$ these panels were placed in the field for 1 or $2 \mathrm{~d}$ and then returned to the laboratory. The number of individuals on each panel was counted 
and then the panel was assigned to a density treatment of 1 to 100 individuals per panel. Any excess individuals were haphazardly removed from each panel. Each panel was then returned to the field either with 1 or 0 individuals of 1 of the predator species. After 2 or $3 \mathrm{~d}$ the number of surviving individuals was counted on all panels. Preliminary regression analyses were conducted for each treatment (control, Anachis lafresnayi, or Mitrella lunata) in each experiment to test whether a relationship existed between percent survivorship of each prey species and its initial density. In no case were any of the regressions significant, all but $3 \mathrm{r}^{2}$ values were less than 0.1 (maximum $\mathrm{r}^{2}=0.21$ ), and slopes ranged between 0.005 and -0.003 . Therefore, all densities were pooled within any given treatment and the effects of the treatments on percent survivorship were analyzed using a 1-way ANOVA. Survivorship data for all analyses were transformed using an arcsinesquare-root transformation (Sokal \& Rohlf 1981).

\section{RESULTS}

\section{Main experiments}

As in previous experiments (Osman et al. 1992), 6 taxa recruited in sufficient abundance to analyze. These were the colonial ascidians Botryllus schlosseri, Botrylloides diegensis, and Diplosoma sp., the colonial bryozoans Cryptosula pallasiana and Bugula turrita, and serpulid polychaetes of the genus Spirorbis. The recruitment rate of all 6 sessile taxa fluctuated throughout the summer and autumn of 1991 and 1992, causing recruitment densities for all prey species to vary significantly among the experiments (Table 2 ). In general, B. schlosseri and B. turrita recruitment on control surfaces peaked first, usually in late July or early August, followed by peaks in Diplosoma sp. and B. diegensis in mid- to late August, and finally by a peak in Spirorbis spp. recruitment in late August or early September (Figs. 1 to 3). The recruitment of C. pallasiana showed no distinct peak, but nevertheless, significant differences among experiments were found. Recruitment of all species rapidly declined in September and was very low in October when the study was terminated.

Anachis lafresnayi predation on recruits was fairly consistent, regardless of fluctuations in the relative abundances of potential prey. Based on the analyses of individual experiments in both 1991 (Fig. 1) and 1992 (Fig. 2), A. lafresnayi had strong, significant, negative effects on the abundances of both Botryllus schlosseri and Diplosoma sp. recruits. Except when mean recruitment onto control surfaces of panels was extremely low $\left(<1\right.$ panel $\left.^{-1}\right)$, the number of either B. schlosseri or Diplosoma sp. observed on paired surfaces with $A$. lafresnayi was usually less than $20 \%$ of that seen on control surfaces. Contrary to this pattern, no consistent significant differences were observed between the treatments for the other 4 most common species, Botrylloides diegensis, Bugula turrita, Cryptosula pallasiana, and Spirorbis spp. Except for B. diegensis, these results are also supported by the overall analyses of the 1991 and 1992 data (Table 2). Despite highly

Table 2. Anachis lafresnayi and Mitrella lunata. Comparison of control and predator treatments for experiments conducted in 1991 and 1992. Data for each prey species were analyzed separately for experiments conducted with each of the predators. Results are based on mixed-model 2-way ANOVAs (treatment $\times$ experiment). Mean numbers of recruits found are given; pairs of values in bold type are not significantly different. pexpt: probability that means for experiments (= dates) were not different; $\mathrm{p}_{\text {int }}$ : probability that the interaction term was not significant. Data were log-transformed for the analyses but the means of untransformed data are shown

\begin{tabular}{|c|c|c|c|c|c|c|}
\hline \multirow[t]{2}{*}{ Prey species } & \multicolumn{3}{|c|}{ A. lafresnayi } & \multicolumn{3}{|c|}{ M. lunata } \\
\hline & Control & Predator & $\mathrm{p}$ & Control & Predator & $\mathrm{p}$ \\
\hline Botryllus schlosseri & 3.86 & 0.78 & $\begin{aligned} p_{\text {expt }} & <0.0001 \\
p_{\text {int }} & <0.0001\end{aligned}$ & 3.11 & 0.34 & $\begin{aligned} p_{\text {expt }} & <0.0001 \\
p_{\text {int }} & <0.0001\end{aligned}$ \\
\hline Diplosoma sp. & 5.43 & 0.70 & $\begin{aligned} p_{\text {expt }} & <0.0001 \\
p_{\text {int }} & <0.0001\end{aligned}$ & 4.79 & 1.05 & $\begin{aligned} P_{\text {expt }} & <0.0001 \\
p_{\text {int }} & <0.0001\end{aligned}$ \\
\hline Botrylloides diegensis & 0.52 & 0.30 & $\begin{aligned} p_{\text {expt }} & <0.0001 \\
p_{\text {int }} & >0.40\end{aligned}$ & 0.48 & 0.33 & $\begin{aligned} p_{\text {expt }} & <0.0001 \\
p_{\text {int }} & <0.0030\end{aligned}$ \\
\hline Cryptosula pallasiana & 1.11 & 1.09 & $\begin{aligned} p_{\text {expt }} & <0.0001 \\
p_{\text {int }} & >0.85\end{aligned}$ & 0.97 & 0.34 & $\begin{aligned} \mathrm{p}_{\text {expt }} & <0.0001 \\
\mathrm{p}_{\text {int }} & <0.0010\end{aligned}$ \\
\hline Bugula turrita & 3.97 & 3.81 & $\begin{aligned} p_{\text {expt }} & <0.0001 \\
p_{\text {int }} & >0.50\end{aligned}$ & 2.91 & 1.77 & $\begin{aligned} p_{\text {expt }} & <0.0001 \\
p_{\text {int }} & >0.06\end{aligned}$ \\
\hline Spirorbis spp. & 8.31 & 7.92 & $\begin{aligned} p_{\text {expt }} & <0.0001 \\
p_{\text {int }} & >0.75\end{aligned}$ & 9.07 & 8.80 & $\begin{aligned} p_{\text {expt }} & <0.0001 \\
p_{\text {int }} & >0.50\end{aligned}$ \\
\hline
\end{tabular}



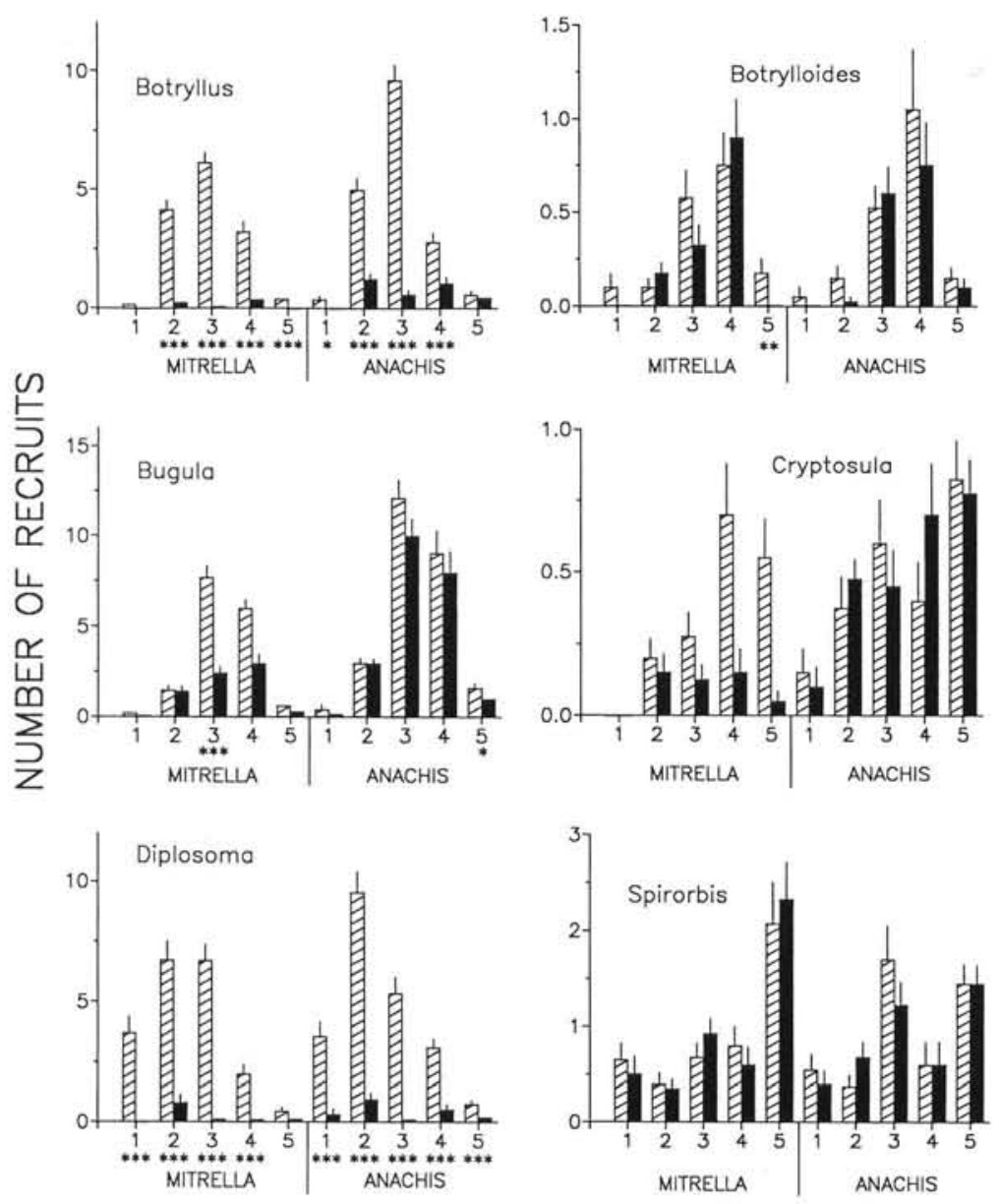

\section{EXPERIMENTS}

Fig. 1. Anachis lafresnayi and Mitrella lunata. Mean number of recruits in the 1991 predation experiments. Shown are means for paired control (striped bars) and predator (solid bars) treatments for the 6 most common recruiting species: Botryllus schlosseri, Botrylloides diegensis, Diplosoma sp., Bugula turrita, Cryptosula pallasiana, and Spirorbis spp. Separate A. lafresnayi and $M$. lunata experiments were conducted at the same time. Expts 1 and 4 were run for $10 \mathrm{~d}$ and the remaining experiments were run for $18 \mathrm{~d}$ (see 'Methods'). All means are expressed for an $8 \mathrm{~d}$ period (the actual exposure time during a $10 \mathrm{~d}$ experiment). Each pair of bars represents the means (+ SE) for an individual experiment. Differences between paired control and predator treatments were analyzed in each experiment using a paired $t$-test: ${ }^{*} \mathrm{p}<0.05$,

$$
\cdots p<0.01, \cdots p<0.001
$$

significant differences among experiments and highly significant interactions between treatment and experiment effects, the mean recruitment of $B$. schlosseri and Diplosoma sp. was significantly higher on control treatments than on those exposed to A. lafresnayi. In addition, a small, but significantly greater recruitment of $B$. diegensis to control treatments than to A. lafresnayi treatments was found.

From the results of the analyses of individual experiments, the effect of Mitrella lunata on recruitment was similar, but not identical, to that observed for
Anachis lafresnayi. In particular, the effects of $M$. lunata on recruitment were more variable than those of $A$. lafresnayi. For example, as with $A$. lafresnayi, the recruitment of both Botryllus schlosseri and Diplosoma sp. was significantly reduced in the presence of $M$. lunata, both in 1991 (Fig. 1) and 1992 (Fig. 3). M. lunata is a known predator of B. schlosseri (Russell-Hunter \& Brown 1964, Milkman 1967) and, except for experiments conducted at very low recruitment densities $\left(<1\right.$ panel $\left.^{-1}\right), M$. Iunata appeared to eliminate almost all recruiting $B$. schlosseri. In fact, except for Expts 7 to 9 in 1992, B. schlosseri recruitment was significantly reduced in the presence of $M$. lunata even when recruitment rates were low on controls. The effect of $M$. lunata on Diplosoma sp. recruitment, although strong, did vary. In the 1991 experiments (Fig. 1), Diplosoma sp. densities averaged less than 10 ind. wk ${ }^{-1}$ and $M$. lunata was able to eliminate almost all recruits. However, in 1992, when the number of Diplosoma sp. recruiting approached 20 ind. $\mathrm{wk}^{-1}$, no significant effect of $M$. lunata was found. This is similar to 1990 experiments in which high Diplosoma sp. recruitment resulted in $M$. lunata having no significant effect (Osman et al. 1992).

Unlike Anachis lafresnayi, Mitrella lunata also appeared to have a limited effect on the recruitment of Bugula turrita and Cryptosula pallasiana in 1992. The apparent effect on B. turrita was fairly slight, resulting in a possible loss of 1 recruit panel ${ }^{-1}$ in any experiment. This difference was only significant when $B$. turrita recruitment rates were less than 3 ind. $\mathrm{wk}^{-1}$ panel $^{-1}$. The differences between the treatments in the recruitment of C. pallasiana were also less than 1 recruit in any experiment. However, because C. pallasiana recruitment was always less than 3 ind. wk $^{-1}$ panel $^{-1}$ in any experiment, this difference was significant in 7 of the 15 experiments (Fig. 3). Recruitment of $C$. pallasiana was always lower in the presence of $M$. lunata in all experiments from both years.

The results of the overall analyses (Table 2) also indicate an effect of Mitrella lunata on the recruitment of these same 4 species, despite the highly significant temporal variation in recruitment. Strong interactive 
effects between treatment and experiment effects were also found for the 4 species, again reflecting the variability in the effects of $M$. lunata on these 4 species that can be seen in Figs. 1 \& 3 .

The results of the stepwise regressions (Table 3) indicate that estimates of predation rate on any particular species were not greatly influenced (if at all) by fluctuations in the recruitment of the other species. Although significant relationships were found, partial $\mathrm{R}^{2}$ values were usually less than 0.1 , suggesting that other species accounted for less than $10 \%$ of the variation in the mortality attributed to predation. The only exceptions were the negative effect of Cryptosula pallasiana on the measured Anachis lafresnayi predation of Diplosoma sp. and the negative effect of Botrylloides diegensis on the predation of Diplosoma sp. and C. pallasiana by Mitrella lunata. Since A. lafresnayi had no significant effect on the recruitment of C.'pallasiana and $M$. lunata had no significant effect on $B$. diegensis, preferential predation on these species is not the likely mechanism for their association with reduced predation mortality of the other species. The recruitment rates of $C$. pallasiana and $B$. diegensis were also the lowest of the 6 taxa and it seems unlikely that their negative effect could have resulted from a physical interference with the gastropods' ability to locate prey. Given no obvious mechanism to explain these weak correlations, it is likely that there was no causative relationship.

Finally, the results for the Lacuna vincta experiments are shown in Fig. 4. Unlike either of the predators, no significant decreases in recruitment were observed in the presence of this gastropod. Significant effects were seen for Spirorbis spp., but these actually resulted from slightly higher recruitment of these polychaetes in the presence of the $L$. vincta.

\section{Prey selection and effects on recruitment}

Although both Anachis lafresnayi and Mitrella lunata preyed principally on Botryllus schlosseri and Diplosoma sp., we examined whether there were any significant differences in their prey selection and the overall effect on the community of recruits. Because Spirorbis spp. recruited in large numbers and was clearly not a prey item of either species of gastropod (Figs. 1 to 3), it was not included in any comparisons.

Based on the comparisons of recruitment distributions on control and treatment panels (Fig. 5), both species clearly changed the overall patterns of recruitment. For the most part, the fairly selective predation by Anachis lafresnayi on Botryllus schlosseri and Diplosoma sp. resulted in significantly different distributions of recruits on the treatment and control surfaces throughout most of the recruitment season. Except for experiments at the beginning and end of the summer when ascidian recruitment was very low, $A$. lafresnayi shifted recruitment from being dominated by ascidians to being dominated by bryozoans. The pattern for Mitrella lunata was fairly similar to that of A. lafresnayi, except that during times of high Diplosoma sp. recruitment (particularly Expt 8), M. lunata 


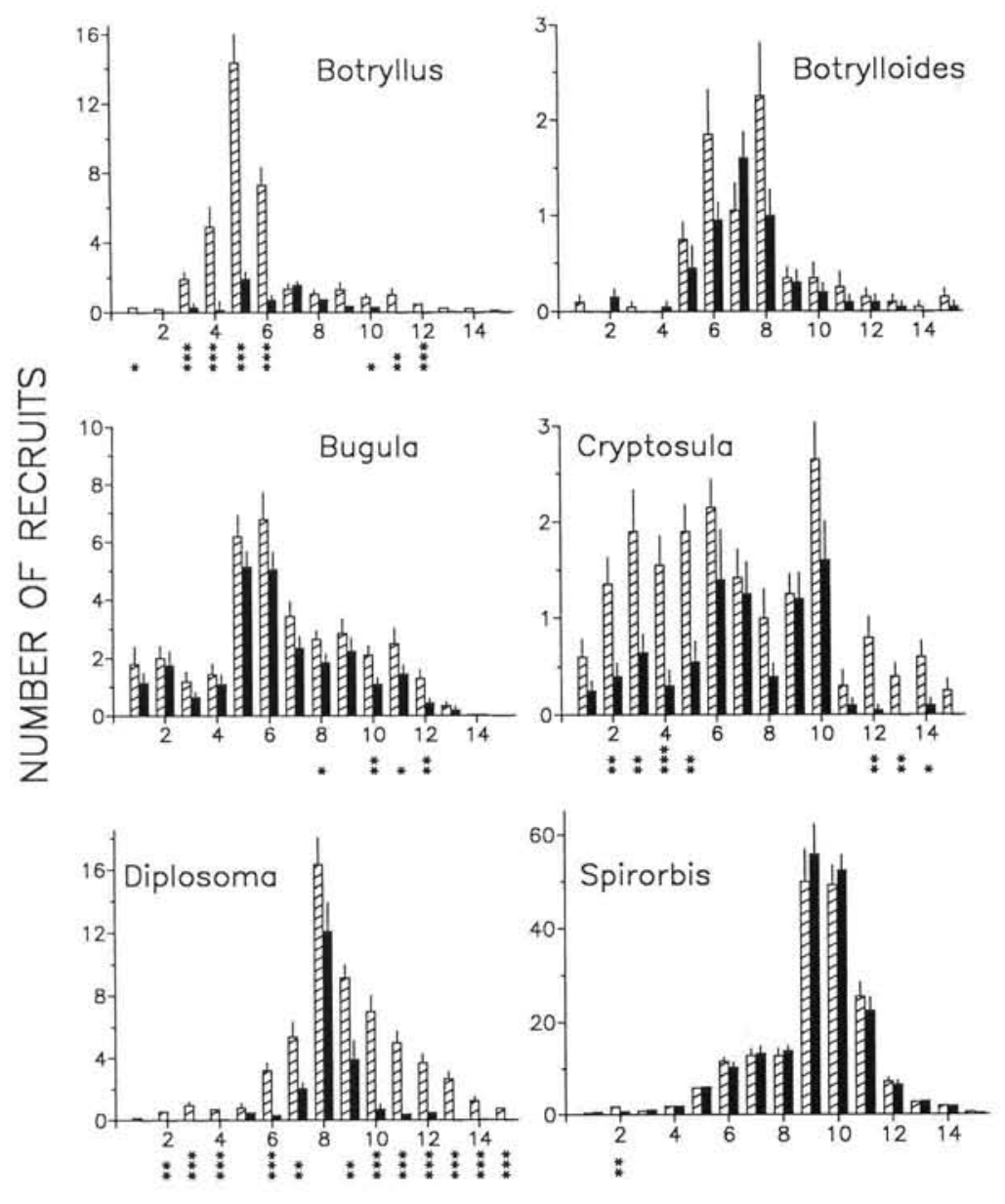

1992 MITRELLA EXPERIMENTS

Fig. 3. Mitrella lunata. Mean number of recruits in the 1992 predation experiments. All experiments were run in overlapping $10 \mathrm{~d}$ periods from 30 June to 29 October 1992. See Fig. 1 for complete description and prey species names

\section{Effect of co $^{\top}$ y size}

Based on the rf ts of the 4-way ANOVA (Table 4), t mortality of Diplosoma sp. in the experiment was significantly greater than the mortality of Botryllus schlosseri (Fig. 7). The mortality of both prey species was also significantly greater for small colonies and for colonies in the presence of the predatory snails. However, no significant differences were found between Anachis lafresnayi and Mitrella lunata in their effect on prey mortality.

The only significant interaction term in the analysis was for treatment $x$ colony size. The cause of this can be seen in Fig. 7. For Diplosoma sp. in the presence of Mitrella lunata, and Botryllus schlosseri in the presence of both predators, the mortality of small colonies was disproportionally greater than that of large colonies when contrasted to differences between colony sizes in control treatments. This pattern is particularly obvious for Diplosoma sp. in the presence of M. Iunata in which the mortality of large colonies with the predator was not substantially greater than either large or small colonies in the control treatment. This contrasts with small colonies which suffered $>95 \%$ mortality in the presence of $M$. lunata. For $B$. schlosseri, mortality was higher for small colonies in the presence of both predators while there was almost no mortality of either large or small colonies in the control treatments.

It would thus appear that there may be an escape in size for Botryllus schlosseri recruits from both species of predators, but given the high variability it is unclear what size is sufficient to reduce overall mortality. For Diplosoma sp., an increase in size clearly results in very significant reductions in mortality from Mitrella lunata predation, but no escape from Anachis lafresnayi. It cannot be determined from these studies whether A. lafresnayi predation continues to have any effect on colonies older than $1 \mathrm{wk}$.

\section{Predation on rarer recruits}

Several common species within the local community were too small as newly settled individuals for us to identify reliably. In particular, the 3 very common soliA. lafresnayi during the time of these 4 experiments. 
Table 3. Anachis lafresnayi and Mitrella lunata. Results of stepwise regression examining the effect of the initial recruitment densities of the 6 most abundant recruiting species on the estimated percent mortality resulting from predation from the 2 predators. Only species having $\mathrm{p}<0.05$ were entered into the regression models. Species are listed in the order that they were entered. Partial $\mathrm{R}^{2}$ and coefficient estimates are for the full model

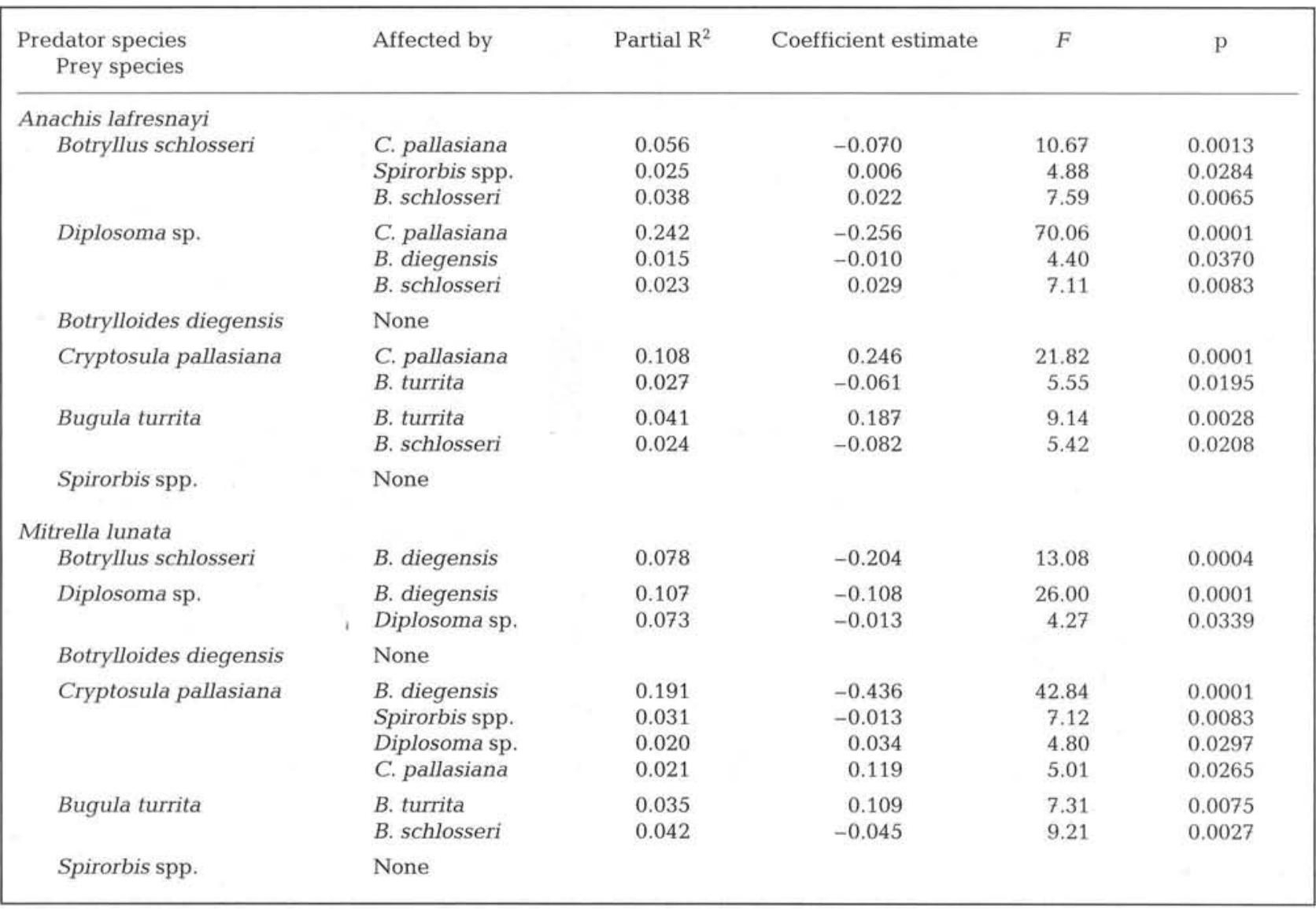

tary ascidians at our study site, Ciona intestinalis, Molgula manhattensis, and Styela clava, could not be distinguished consistently as recruits. In addition, the recruitment rate of Botrylloides diegensis was also fairly low, reducing our ability to detect any effect of the predators on its recruitment. Results from the experiments in which recruitment densities of each of these species were manipulated can be used to examine the potential effects of the predators on these 4 species (Fig. 8).

In Fig. 8 we have included the results of an experiment conducted with Botryllus schlosseri as reference. In this experiment the predation rate by Anachis lafresnayi on newly settled B. schlosseri colonies was very similar to that observed in the recruitment experiments (Figs. 1, 2 \& 5) as well as in the size experiment (Fig. 7). Control and A. lafresnayi panels were significantly different $\left(F_{1,145}=12.66, \mathrm{p}<0.001\right)$. It can also be seen that $A$. lafresnayi continued to remove 50 to $60 \%$ of all B. schlosseri at densities well exceeding those we observed in the main field experiments.
The results of the Botrylloides diegensis experiment (Fig. 8) also confirmed the paired $t$-test analyses of the main recruitment experiments (Figs. $1 \& 2$ ), but differed from the results of the overall analyses (Table 2). Anachis lafresnayi had no significant effect on $B$. diegensis mortality $\left(F_{1,95}=2.40, \mathrm{p}>0.10\right)$, even when densities were increased well beyond the 2 to 3 ind. panel $^{-1}$ that we observed in the main experiments.

The results for Molgula manhattensis and Styela clava are very similar. Anachis lafresnayi had no significant effect on survival of recruits of either $M$. manhattensis $\left(F_{1,51}=0.04, \mathrm{p}>0.80\right)$ or $S$. clava $\left(F_{1,186}=1.32\right.$, $\mathrm{p}>0.25)$. In contrast, Mitrella lunata had significant and strong effects on both $M$. manhattensis $\left(F_{1,91}=\right.$ $75.0, \mathrm{p}<0.0001)$ and $S$. clava $\left(F_{1,109}=32.77, \mathrm{p}<0.0001\right)$, virtually eliminating them at all densities (Fig. 8).

Finally, the results for Ciona intestinalis are not as clear, mainly resulting from abnormally low survival on control panels. However, Mitrella lunata did have a significant effect on $C$. intestinalis recruitment $\left(F_{1,103}=\right.$ $25.73, \mathrm{p}<0.0001$ ), but perhaps not to the magnitude 

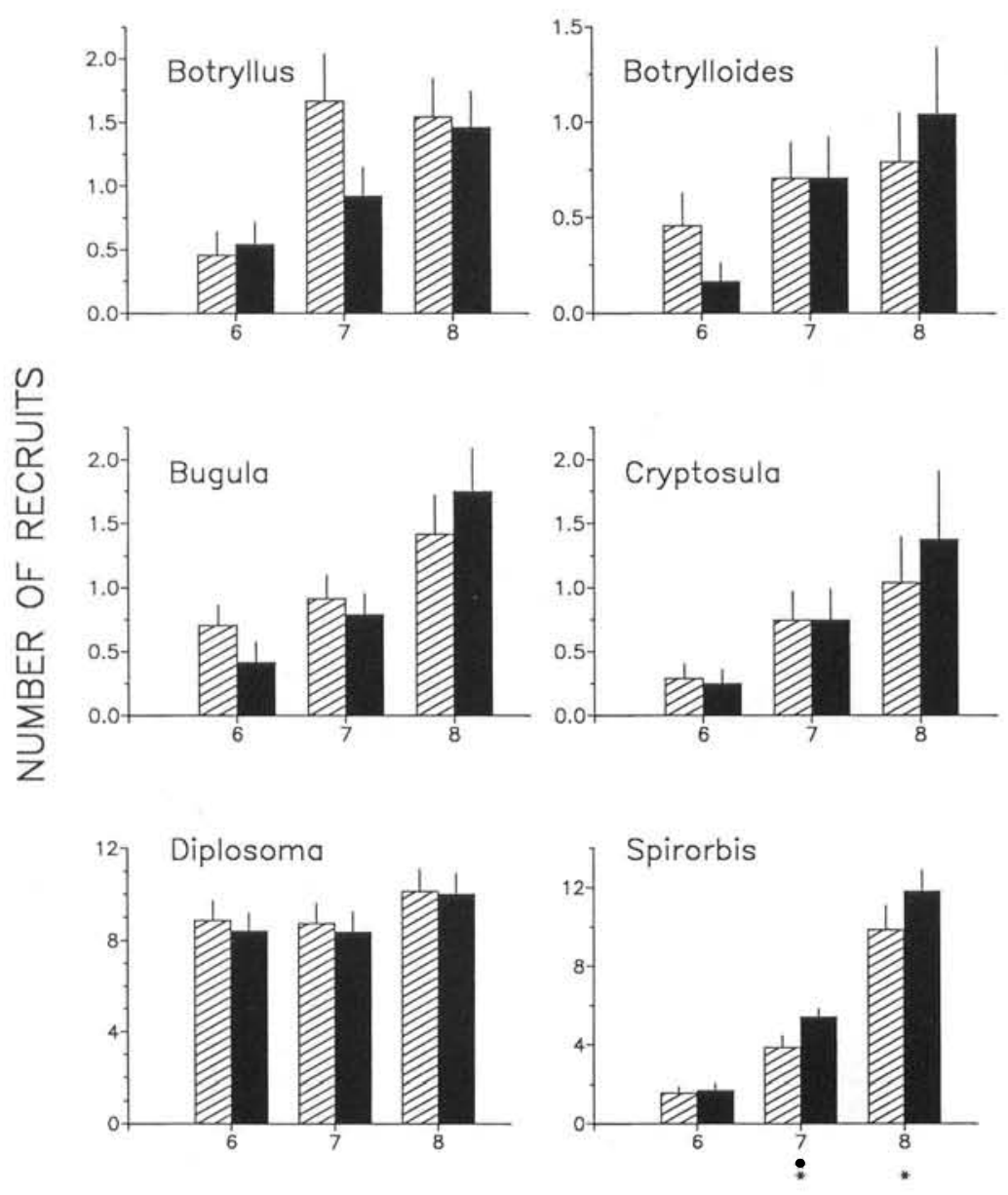

1992 LACUNA EXPERIMENTS

Fig. 4. Lacuna vincta. Mean number of recruits in the 1992 predation experiments. Experiments correspond to Expts 6 to 8 in Figs. 2 \& 3. See Fig. 1 for complete description and prey species names

that it had when preying on Molgula manhattensis and Styela clava. No significant effect was discerned for Anachis lafresnayi $\left(\mathrm{F}_{1,61}=3.16, \mathrm{p}>0.05\right)$ preying on $C$. intestinalis.

\section{DISCUSSION}

Although the potential influence of post-settlement events on observed patterns of recruitment into benthic invertebrate communities is usually acknowledged, only a few studies have attempted to examine the magnitude and importance of processes which occur in the relatively short time period between settlement and recruitment (e.g. Grosberg 1981, Underwood \& Denley 1984, Wethey 1984, 1986, Caffey 1985, Connell 1985, McGuinness \& Davis 1989, Stoner 1990).
This is in sharp contrast to the large number of studies that have focused on the causes of mortality in early post-settlement algal life stages (reviewed by Vadas et al. 1992).

Our initial examination of the role of 2 tiny predators commonly associated with rocky subtidal sessile invertebrate communities (Osman et al. 1992) suggested that selective predation on newly settled colonial ascidians could alter the relative abundances of recruiting species and the community that eventually developed. The present study more rigorously evaluated these findings and examined the impact of post-settlement predation in a broader context. Specifically, we examined (1) whether the effects of the 2 species of micro-predators changed with annual or seasonal variation in larval settlement, (2) whether the 2 species of predators differed in their selection of prey, and (3) whether the prey species had an escape in size that would limit the predator's influence.

\section{Temporal change}

It is clear from Figs. 1 to 3 , as well as from the analyses summarized in Table 2 , that the recruitment of all the species fluctuated significantly throughout the summer as well as between years. Significant interaction effects between treatments and experiments (Table 2) also indicate that the effect of the predators on prey species varied temporally. Overall, this variability was in the magnitude of the effects, not the nature of the relationships. Both predators continued to have a significant effect on recruitment throughout the recruitment season (July to October) of their principal sessile prey, Botryllus schlosseri and Diplosoma sp. (Figs. 1 to 3 ).

Anachis lafresnayi preyed consistently on Botryllus schlosseri and Diplosoma sp. and removed almost all individuals of both species regardless of seasonal or year-to-year changes in recruitment density. The single-prey-species experiment conducted with $B$. schlosseri (Fig. 8) also demonstrated that even if $B$. schlosseri recruited at much higher densities than we have ever observed at any of our study sites, A. lafresnayi could continue to remove the majority of those individuals recruiting. For example, the highest natural settlement rate that we have observed for $B$. 


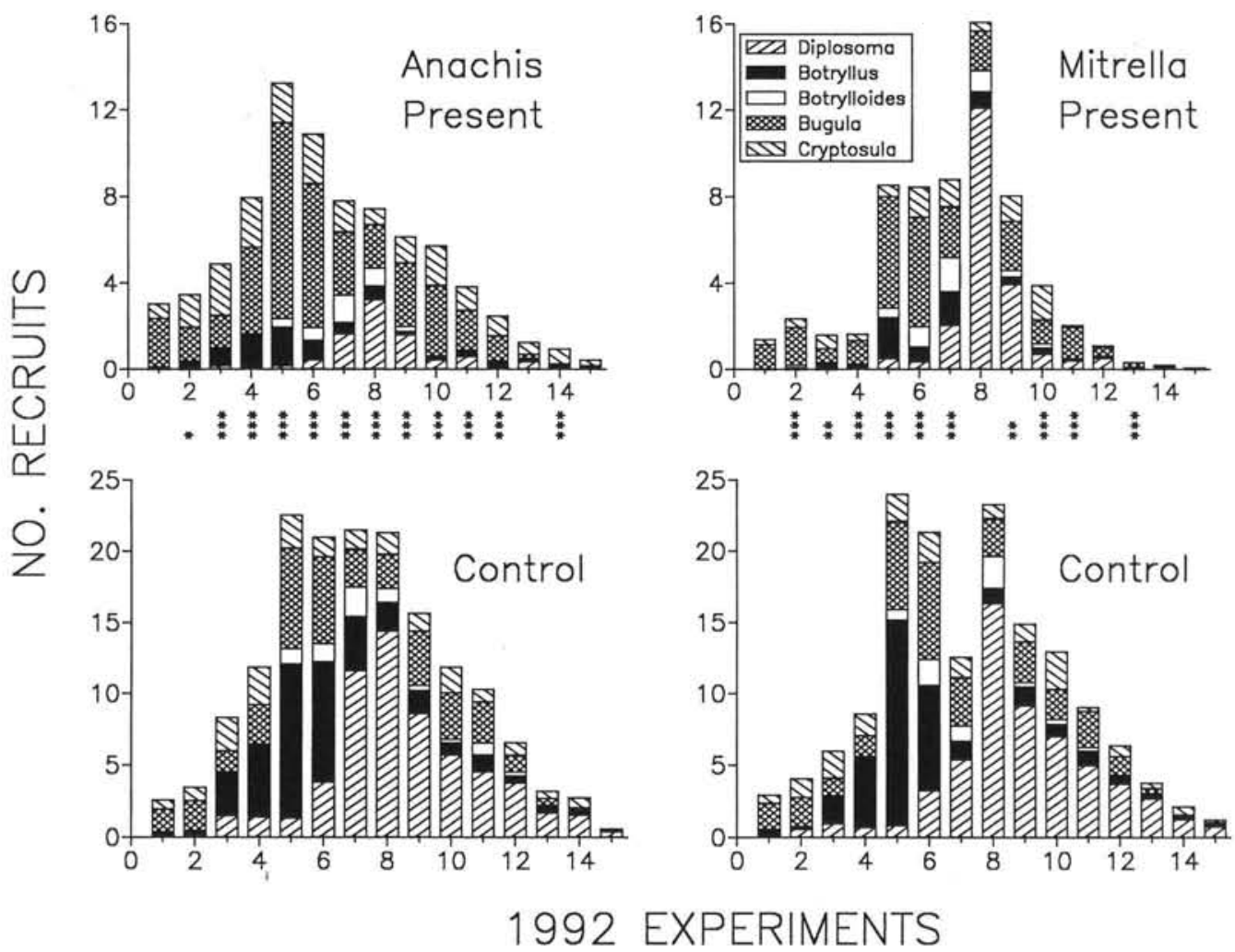

Fig. 5. Anachis lafresnayi and Mitrella lunata. Comparison of the species distribution of available prey as observed on control surfaces to the distribution of recruits in the presence of the 2 predators. Comparisons were made for each experiment using a G-test: ${ }^{*} \mathrm{p}<0.05, \cdots \mathrm{p}<0.01, \cdots \mathrm{p}<0.001$. See Fig. 1 for prey species names

Table 4. Anachis lafresnayi and Mitrella lunata. Results of the 4-way analysis of variance for the effects of colony size on predation by the 2 predators on the 2 prey species, Diplosoma sp. and Botryllus schlosseri, in treatments with and without the predators present. The dependent variable was percent survivorship of the prey species and all data were transformed for the analysis using an arcsine-square-root transformation

\begin{tabular}{|c|c|c|c|c|c|}
\hline Source & df & SS & MS & $F$ & $\mathrm{p}$ \\
\hline \multicolumn{6}{|l|}{ Main effects } \\
\hline Prey & 1 & 0.6846 & 0.6846 & 6.85 & 0.0112 \\
\hline Predator & 1 & 0.1258 & 0.1258 & 1.26 & 0.2663 \\
\hline Treatment & 1 & 12.7268 & 12.7268 & 127.36 & 0.0001 \\
\hline Colony Size & 1 & 2.0229 & 2.0229 & 20.24 & 0.0001 \\
\hline \multicolumn{6}{|l|}{ 2-way interactions } \\
\hline Prey $\times$ Predator & 1 & 0.0280 & 0.0280 & 0.28 & 0.5968 \\
\hline Prey $\times$ Treatment & 1 & 0.0656 & 0.0656 & 0.66 & 0.4211 \\
\hline Prey $\times$ Colony Size & 1 & 0.0443 & 0.0443 & 0.44 & 0.5079 \\
\hline Predator $\times$ Treatment & 1 & 0.0695 & 0.0695 & 0.70 & 0.4074 \\
\hline Predator $\times$ Colony Size & 1 & 0.0571 & 0.0571 & 0.57 & 0.4528 \\
\hline Treatment $\times$ Colony Size & 1 & 1.6299 & 1.6299 & 16.31 & 0.0002 \\
\hline \multicolumn{6}{|l|}{ 3-way interactions } \\
\hline Prey $\times$ Predator $\times$ Treatment & 1 & 0.1603 & 0.1603 & 1.60 & 0.2101 \\
\hline Prey $\times$ Predator $\times$ Colony Size & 1 & 0.0655 & 0.0655 & 0.66 & 0.4212 \\
\hline Prey $\times$ Colony Size $\times$ Treatment & 1 & 0.0498 & 0.0498 & 0.50 & 0.4830 \\
\hline Predator $\times$ Colony Size $\times$ Treatment & 1 & 0.2674 & 0.2674 & 2.68 & 0.1070 \\
\hline \multicolumn{6}{|l|}{ 4-way interactions } \\
\hline Prey $\times$ Predator $\times$ Colony Size $\times$ Treatment & 1 & 0.3683 & 0.3683 & 3.69 & 0.0596 \\
\hline Error & 61 & 6.0958 & 0.0999 & & \\
\hline
\end{tabular}




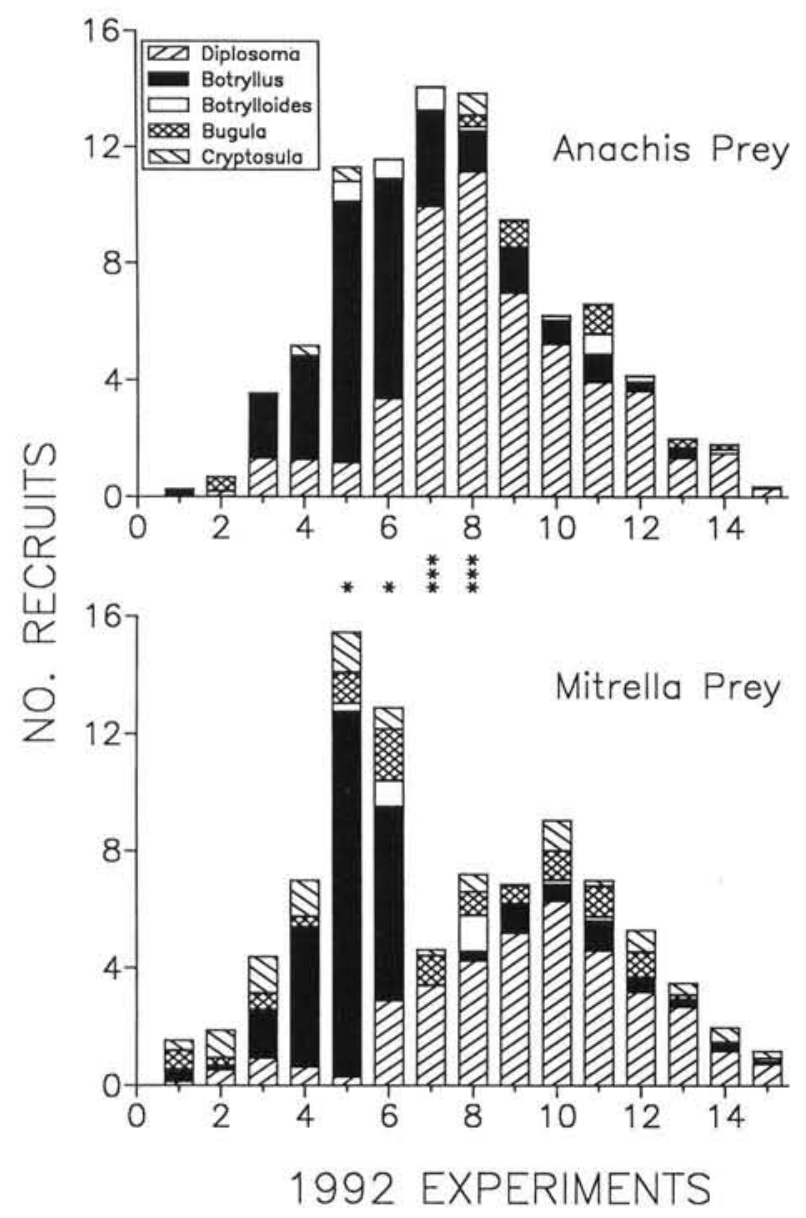

Fig. 6. Anachis lafresnayi and Mitrella lunata. Comparison of the estimated distribution of prey assumed eaten by the 2 predators. As an estimate of the number of each prey species consumed, we used the differences between paired control and treatment surfaces. Comparisons were made for each experiment using a $G$-test: ${ }^{*} \mathrm{p}<0.05,{ }^{\cdots} \mathrm{p}<0.01,{ }^{\cdots} \mathrm{p}<0.001$. See Fig. 1 for prey species names

schlosseri was 1 ind. $\mathrm{cm}^{-2} \mathrm{~d}^{-1}$ (measured as 200 ind. $100 \mathrm{~cm}^{-2} 2 \mathrm{~d}^{-1}$ in 1988 in Eel Pond, Woods Hole, Massachusetts, USA; Osman et al. 1992). This is equivalent to an initial prey density of $\sim 40 \mathrm{~B}$. schlosseri in the single-species experiment ( 40 ind. $19 \mathrm{~cm}^{-2} 2 \mathrm{~d}^{-1}$ ). Given that A. lafresnayi continued to have a significant effect on B. schlosseri recruitment at densities 2.5 times this rate (Fig. 8), it appears that A. lafresnayi is capable of ingesting most, if not all, B. schlosseri even during peak periods of recruitment.

Predation by Mitrella lunata on recruits was more variable, both in response to temporal changes in prey abundances and in the types of prey species consumed. In both 1991 and 1992 M. lunata removed most of the Botryllus schlosseri recruits, regardless of changes in recruitment rates. However, $M$. lunata pre- dation on Diplosoma sp. had no significant effect during the peak in Diplosoma sp. recruitment. This was also seen in experiments conducted in 1990 (Osman et al. 1992), suggesting that $M$. lunata may have little effect at high recruitment abundances of this prey species. However, it is important to note that $M$. lunata both consumed almost all B. schlosseri when it recruited at a similar peak rate and consumed most recruits of several species of solitary ascidians at much higher densities. This suggests that $M$. lunata is not necessarily 'swamped' by an over-abundance of recruiting Diplosoma sp., particularly since the abundance of the alternate prey species, B. schlosseri, had declined sharply. The inability of $M$. lunata to influence Diplosoma sp. must either be a more complex response to a combination of processes such as high
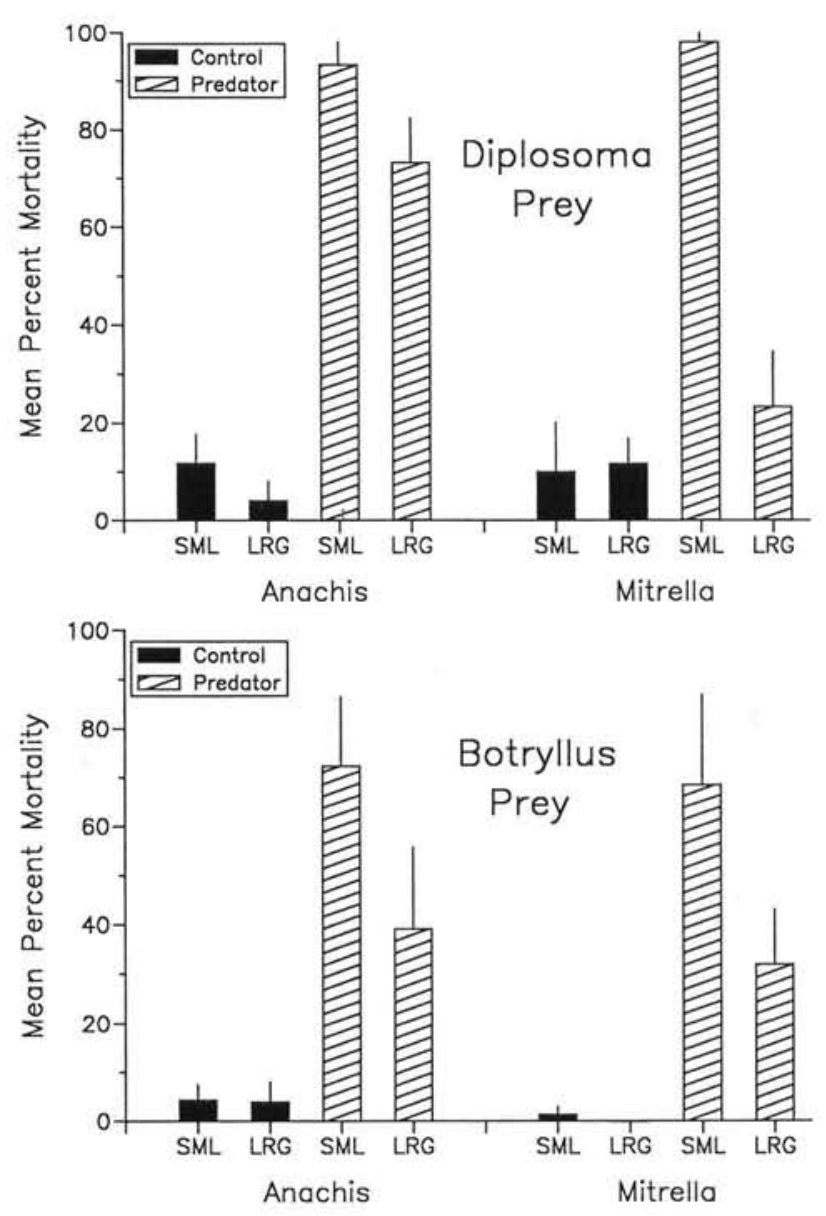

Prey Size and Predator

Fig. 7. Anachis lafresnayi and Mitrella lunata. Comparison of mortality of large and small ascidian colonies in the presence of the 2 predators. The experiment was conducted with the 2 main prey species, Diplosoma sp. and $E$ tryllus schlosseri 
settlement coupled with high colony growth rate that would allow a high proportion of recruits to reach a size $M$. lunata cannot consume (Fig. 7) or an unmeasured change in the gastropod that would reduce ingestion rate (e.g. increased reproductive activity).

\section{Prey selectivity}

In most experiments both predators removed almost all recruits of Botryllus schlosseri and Diplosoma sp. and the results of the stepwise regressions (Table 3) show that this predation was unaffected by changes in the recruitment of other species. Thus, as the relative abundances of the 2 prey species changed, a similar change was seen in the diets of the 2 predators. In the early summer B. schlosseri was the principal prey of both predators. Later, as $B$. schlosseri recruitment declihed and Diplosoma sp. recruitment increased, Diplosoma sp. became the principal prey of both gastropods (Fig. 6).

The predators did differ in the degree to which they preyed on other species. Anachis lafresnayi had no effect on any other species, whereas Mitrella lunata appeared to prey on bryozoans. However, the bryozoans only formed a small proportion of the diet of M. lunata (Fig. 6) and the overall effect was minimal (Fig. 5). The results of the single-species experiments (Fig. 8), also suggest that $M$. lunata, unlike $A$. lafresnayi, did consume recruits of the 3 most common solitary ascidians, Molgula manhattensis, Styela clava, and Ciona intestinalis. The experiments also demonstrate that $M$. lunata is capable of completely consuming all 3 species at extremely high densities, unlike its response to Diplosoma sp.

Finally, neither species preyed on Spirorbis spp. and any effect on Botrylloides diegensis was weak, at best. With the results of the single-species experiments (Fig. 8) contradicting the weak effect of Anachis lafresnayi on $B$. diegensis seen in Table 2, the recently introduced $B$. diegensis was the only species of ascidian which escaped any strong effect on its recruitment by either predator. Occasionally we did observe partially eaten individuals and strands of tissue from eaten $B$. diegensis, but this predation had no measurable effect.
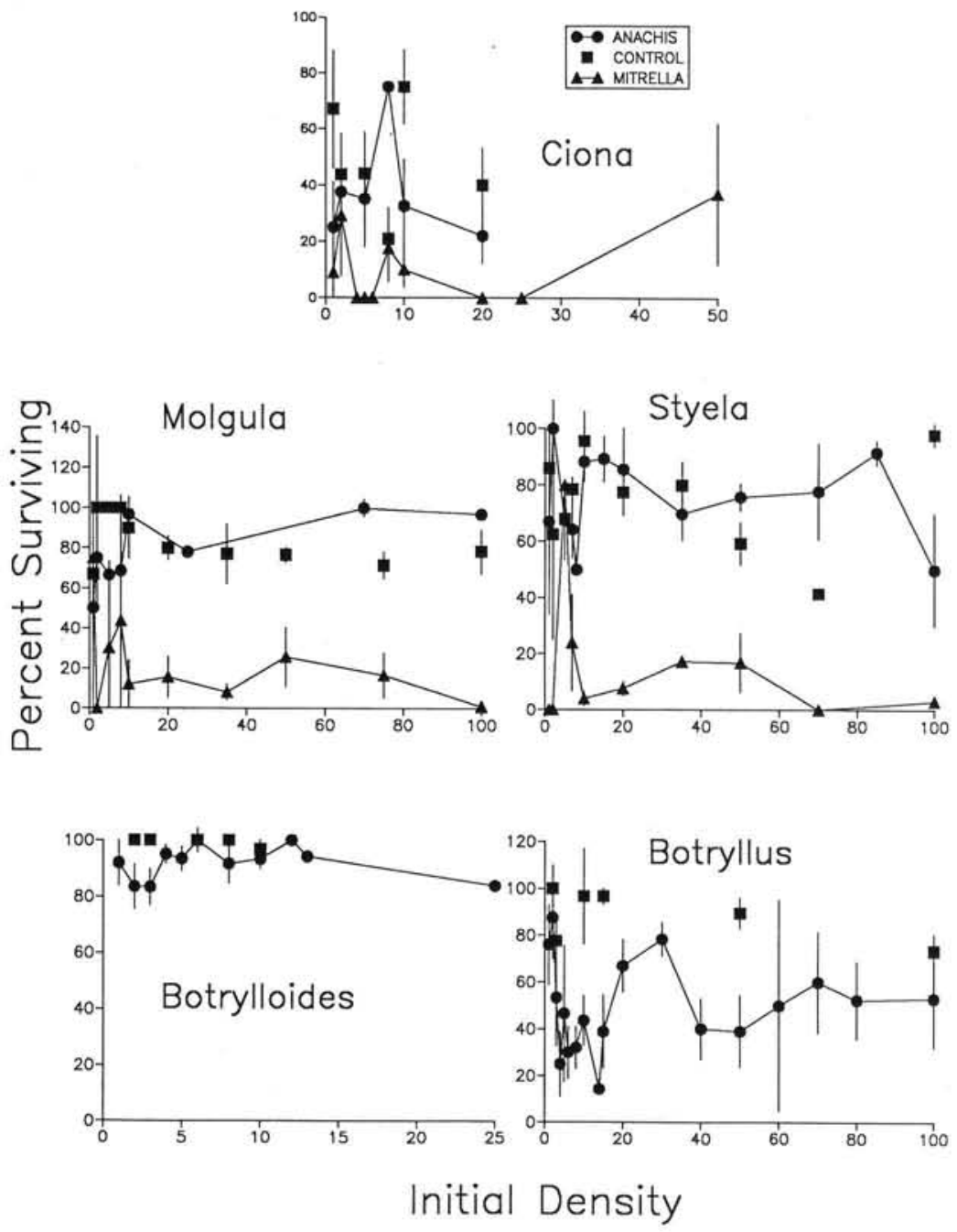

Fig. 8. Anachis lafresnayi and Mitrella lunata. Comparison of the survival of ascidian recruits (Ciona intestinalis, Molgula manhattensis, Styela clava, Botrylloides diegensis, and Botryllus schlosseri) in the presence of the 2 predators. ans $( \pm \mathrm{SE})$ are shown for each starting density used in a given experiment. o $M$. lunata treatments were used in the $B$. diegensis and B. schlosseri experiments. Lines connecting means are for clarity and imply no relationships

\section{Prey size}

The results of the size experiments (Table 4, Fig. 7) indicate that both of the principal prey species may ultimately reach a size at which they are no longer vulnerable to predation by Anachis lafresnayi and/or Mitrella lunata. The size of Botryllus schlosseri had the same effect on both predators. Colonies that were 7 to 8 zooids in size and $1 \mathrm{wk}$ old suffered half the mortality observed for 1 to 2 zooid, 1-d-old individuals. On the other hand, most 10 to 11 zooid, 1-wk-old Diplosoma sp. colonies escaped predation by $M$. lunata but not by $A$. lafresnayi. Thus, in habitats where the snails are present, the rapid growth of prey should reduce 
the risk of mortality from these predators with significant reductions not being attained by colonies until they are at least 10 zooids. This should result in both of the principal prey species remaining vulnerable to predation by the gastropods for $1 \mathrm{wk}$ or more, depending on growth rates.

\section{Potential extent of predation effects}

At all the sites in eastern Long Island Sound where we have found these micro-predators (as well as in Vineyard Sound, near Woods Hole; Osman et al. 1992), both species have been present. Both species are commonly found on the same rock or cobble with mean densities very similar to those used in the experiments (Osman et al. 1992). Even though we have not determined whether intra- or interspecific competition affects predation rates, it seems likely that the combined effects of the 2 species on the recruitment of at least Botryllus schlosseri and Diplosoma sp. can be severe and Mitrella lunata alone seems capable of restricting, and possibly eliminating, the recruitment of solitary ascidians.

There is also little evidence that seasonal or yearto-year variations in prey settlement densities can create a temporal refuge from these predators. We have monitored the natural abundances of both species of gastropods at a site approximately $1 \mathrm{~km}$ from our study site and both predators remain abundant throughout the summer recruitment season. With the possible exception of the response of Mitrella lunata to high densities of Diplosoma sp., each predator alone can ingest prey at rates much higher than observed settlement rates. Given that the 2 gastropods co-occur, there seems little likelihood that prey species could successfully recruit on a regular basis by swamping their predators. Likewise, gastropod populations are unlikely to be reduced by starvation resulting from shifts in the relative abundances of prey or even the severe reduction in the recruitment of 1 prey species. Generally, Anachis lafresnayi preys on Botryllus schlosseri and Diplosoma sp. in proportion to their abundances, easily switching from one to the other as relative abundances change. Although $M$. lunata seems less capable of switching between the 2 ascidians, it appears to have a variety of other alternative prey. Thus the predators do not seem dependent on the presence of a particular species or its high recruitment. If this is so then gastropod populations can be maintained at sites during times of low recruitment and continue to affect ascidian recruitment.

Escape in physical refuges may also be unlikely. We conducted our experiments on flat, open substrates that were easily accessible to the predators. It is possible that prey could escape by recruiting into cracks, crevices, or other structures that could not be reached by the snails. However, both predators are small, highly mobile, and quite capable of getting into most areas that are accessible to larvae. In other field experiments we found that cages with $\sim 2 \mathrm{~mm}$ mesh screen are necessary to completely exclude Mitrella lunata and these cages also exclude recruiting larvae.

\section{Relative importance of post-settlement processes}

The importance of post-settlement mortality is dependent on its severity relative to both larval settlement and post-recruitment processes. Although the present experiments demonstrate the potential of postsettlement predation to drastically alter recruitment, they do not contrast these effects with those that might result from differences in larval abundance or settlement which can also influence recruitment (Roughgarden et al. 1985, 1988, Gaines \& Roughgarden 1987). It is also not certain whether the sharp reductions in ascidian recruitment resulting from predation are sufficient to alter later processes that also can affect the species composition and structure of the community that develops.

We do feel that our studies have demonstrated that post-settlement mortality can significantly alter a community by removing most, if not all, recruits of spatially dominant prey species. Certainly, the high rates of settlement that can be observed for barnacles in the rocky intertidal (e.g. MacDougall 1943, Wethey 1984, 1986, Caffey 1985) have the potential to overwhelm any population of micro-predators. However, in communities which are often dominated by species which produce fewer, shorter-lived, and poorly dispersed larvae, predation or other causes of post-settlement mortality can have a much larger importance than settlement. In areas where the ascidians are abundant and are likely to produce the highest settlement rates, the 2 gastropods are able to keep experimental surfaces fairly clean of the recruits of prey species. In other areas where ascidians are less abundant or absent, settlement rates of these species should be much lower and the micro-predators should prevent any increased recruitment and thus any invasion. Given the ability of the ascidians to dominate substrates (e.g. Grave 1933, Sutherland 1974, Osman 1977, Grosberg 1981), it seems reasonable that without the predators a successful invasion of an area is much more likely to eventually occur. However, what is still not clear is the relative importance of existing low settlement rates and post-settlement predation in actually controlling local recruitment. 
Equally important is determining how the changes in recruitment produced by the micro-predators affect the long-term dynamics of the community. The colonial ascidians are commonly dominant competitors in sessile communities, often overgrowing other species (Osman 1977, Grosberg 1981). However, both Botryllus schlosseri and Botrylloides diegensis can be semelparous (Grosberg 1987, R. Malatesta pers. comm.), dying after reproducing. We have also observed Diplosoma sp. colonies dying after overgrowing the entire surface of a substrate. Such patterns obviously free space for other species, potentially allowing a community not dominated by ascidians to develop. Unless the ascidians can recruit into these communities and reestablish dominance (preliminary experiments suggest they can in the absence of micro-predators), then the differences caused by the micro-predators may be short-lived. In addition, an array of other potential micro- and macro-predators exist which can also affect the community dynamics by preying on other sessile species, Anachis lafresnayi, Mitrella lunata, or on each other.

It is thus not clear whether one process operating at one life stage can be singled out as controlling the dynamics of the community. However, we feel that the potential of processes affecting post-settlement life stages to contribute significantly to the overall dynamics is real and must be considered along with the much better documented affects of larval settlement, adult predators, and physical disturbance. Anachis lafresnayi and Mitrella lunata are not the only species and predation is not the only process affecting post-settlement mortality. How ubiquitous and important are the processes affecting recruits is a question that must still be answered.

Acknowledgements. This work was supported by NSF grants OCE-9101815 and OCE-9123890. We thank P. Mitchell, A. Frese, M. Holt, L. Springer, and R. Malatesta for their assistance in the laboratory and the field, G. Gernier for help in designing and constructing experimental apparatus, and D. Breitburg, J. Watanabe, P. Petraitis, and 2 anonymous reviewers for comments on earlier versions of this manuscript. Contribution No. 266 to the Marine Sciences Institute, University of Connecticut.

\section{LITERATURE CITED}

Bertness, M. (1989). Intraspecific competition and facilitation in a northern acorn barnacle population. Ecology 70: $257-268$

Brawley, S. H., Johnson, L. E. (1991). Survival of fucoid embryos in the intertidal zone depends upon developmental stage and microhabitat. J. Phycol. 27: 179-186

Caffey, H. M. (1985). Spatial and temporal variation in settlement and recruitment of intertidal barnacles. Ecol. Monogr. 55: 313-332

Connell, J. H. (1985). The consequences of variation in initial settlement vs, post-settlement mortality in rocky intertidal communities. J. exp. mar. Biol. Ecol. 93: 11-45

Dayton, P. K. (1973). Dispersion, dispersal, and persistence of the annual intertidal alga, Postelsia palmaeformis Ruprecht. Ecology 54: 433-438

Dayton, P. K. (1975). Experimental evaluation of ecological dominance in a rocky intertidal algal community. Ecol. Monogr. 45: 137-159

Dayton, P. K., Tegner, M. J. (1984). The importance of scale in community ecology: a kelp forest example with terrestrial analogs. In: Price, P. W., Slobodchikoff, C. N., Gaud, W. W. (eds.) A new ecology: novel approaches to interactive systems. John Wiley and Sons, New York, p. 457-481

Dean, T. A., Schroeter, S. C., Dixon, J. D. (1984). Effects of grazing by two species of sea urchins (Strongylocentrotus franciscanus and Lytechinus anamesus) on recruitment and survival of two species of kelp (Macrocystis pyrifera and Pterygophora californica). Mar. Biol. 78: 301-313

Dean, T. A., Jacobsen, F. R., Thies, K., Lagos, S. L. (1988), Differential effects of grazing by white sea urchins on recruitment of brown algae. Mar. Ecol. Prog. Ser. 48: 99-102

DeVinny, J. S., Volse, L. A. (1978). Effects of sediments on the development of Macrocystis pyrifera gametophytes. Mar. Biol. 48: 343-348

Deysher, L. E., Dean, T. A. (1986). In situ recruitment of sporophytes of the giant kelp Macrocystis pyrifera (L.) C. A. Agardh: effects of physical factors. J, exp. mar. Biol. Ecol. 103: 41-63

Gaines, S. D., Roughgarden, J. (1987). Fish in offshore kelp forests affect recruitment to intertidal barnacle populations. Science 235: 479-481

Grave, B. H. (1933). Rate of growth, age at sexual maturity, and duration of life of certain sessile organisms at Woods Hole, Massachusetts. Biol. Bull. 65: 375-386

Grosberg, R. K. (1981). Competitive ability influences habitat choice in marine invertebrates. Nature 290: 700-702

Grosberg, R. K. (1987), Limited dispersal and proximitydependent mating success in the colonial ascidian Botryllus schlosseri. Evolution 41: 372-384

Hruby, T., Norton, T. A. (1979). Algal colonization on rocky shores in the Firth of Clyde. J. Ecol. 67: 65-77

Keough, M. J., Downes, B. J. (1982). Recruitment of marine invertebrates: the roles of active larval choices and early mortality. Oecologia 54: 348-352

Luckenbach, M. W. (1984). Settlement and early postsettlement survival in the recruitment of Mulinia lateralis (Bivalvia). Mar. Ecol. Prog. Ser. 17: 245-250

MacDougall, K. D. (1943). Sessile marine invertebrates at Beaufort, North Carolina. Ecol. Monogr. 13: 321-374

McGuinness, K. A., Davis, A. R. (1989). Analysis and interpretation of the recruit-settler relationship. J. exp. mar. Biol. Ecol. 134: 197-202

Milkman, R. (1967). Genetic and developmental studies on Botryllus schlosseri. Biol. Bull. 132: 229-243

Osman, R. W. (1977). The establishment and development of a marine epifaunal community. Ecol. Monogr. 47: 37-63

Osman, R. W., Abbe, G. R. (1994). Post-settlement factors affecting oyster recruitment in the Chesapeake Bay, USA. In Dyer, K. (ed.) Changes in fluxes in estuaries: implications from science to management. Olsen and Olsen Press, Fredensborg (in press)

Osman, R. W., Whitlatch, R. B., Malatesta, R. J. (1992). Potential role of micro-predators in determining recruitment into a marine community. Mar. Ecol. Prog. Ser. 83: 35-43

Osman, R. W., Whitlatch, R. B., Malatesta, R. J., Zajac, R. N. (1990). Ontogenetic changes in trophic relationships and their effects on recruitment. In: Barnes, M., Gibson, R. N. 
(eds.) Trophic relationships in the marine environment. Proc. 24th Eur. Mar. Biol. Symp. Aberdeen University Press, Aberdeen, p. 117-129

Reed, D. C. (1990). The effects of variable settlement and early competition on patterns of kelp recruitment. Ecology 71: 776-787

Roegner, G. C. (1991). Temporal analysis of the relationship between settlers and early recruits of the oyster Crassostrea virginica (Gmelin). J. exp. mar. Biol. Ecol. 151: 57-69

Roughgarden, J., Gaines, S., Possingham, H. (1988). Recruitment dynamics in complex life cycles. Science 241: $1460-1466$

Roughgarden, J., Iwasa, Y., Baxter, C. (1985). Demographic theory for an open marine population with space-limited recruitment. Ecology 66: 54-67

Russell-Hunter, W., Brown, S. C. (1964). Phylum mollusca. In: Smith, R. I. (ed.) Keys to marine invertebrates of the Woods Hole region. Marine Biological Laboratory, Woods Hole, MA, p. 129-152

Sokal, R. R., Rohlf, F. J. (1981). Biometry. W. H. Freeman and Co., New York

Stoner, D. S. (1990). Recruitment of a tropical colonial ascidian: relative importance of pre-settlement and post-settlement processes. Ecology 71: 1682-1690

Sutherland, J. P. (1974). Multiple stable points in natural communities. Am. Nat. 108: 859-873

Thorson, G. (1966). Some factors influencing the recruitment and establishment of marine benthic communities. Neth.

This article was presented by R. J. Karlson (Senior Editorial Advisor), Newark, Delaware, USA
J. Sea Res. 3: 267-293

Underwood, A. J. (1980). The effects of grazing by gastropods and physical factors on the upper limits of distribution of intertidal macroalgae. Oecologia 46: 201-213

Underwood, A. J., Denley, E. J. (1984). Paradigms, explanations and generalizations in models for the structure of intertidal communities on rocky shores. In: Strong, D. R. Jr, Simberloff, S., Abele, L. G., Thistle, A. B. (eds.) Ecological communities: conceptual issues and the evidence. Princeton Univ, Press, Princeton, NJ, p. 151-180

Vadas, R. L., Sr., Johnson, S., Norton, T. A. (1992). Recruitment and mortality of early post-settlement stages of benthic algae. Brit. Phycol. J. 27:331-351

Watzin, M. C. (1983). The effects of meiofauna on settling macrofauna: meiofauna may structure macrofaunal communities. Oecologia 59: 163-166

Wethey, D. S. (1984). Spatial pattern in barnacle settlement: day to day changes during the settlement season. J. mar. biol. Ass. U.K. 64: 687-698

Wethey, D. S. (1986). Local and regional variation in settlement and survival in the littoral barnacle Semibalanus balanoides (L.): patterns and consequences. In: Moore, P. G., Seed, R. (eds.) The ecology of rocky coasts. Columbia University Press, New York, p. 194-202

Young, C. M., Chia, F. (1984). Microhabitat-associated variability in survival and growth of subtidal solitary ascidians during the first 21 days after settlement. Mar. Biol. 81: 61-68

Manuscript first received: May 9, 1994

Revised version accepted: September 21, 1994 